\title{
Identidad ciborg en la narrativa de Santiago Roncagliolo y Juan Cárdenas: dicotomías de lo orgánico y lo mecánico en la construcción del cuerpo
}

\section{The Cyborg Identity in the Narrative of Santiago Roncagliolo and Juan Cárdenas: the organic and the mechanical dichotomies in the construction of the body}

\author{
Marissa Gálvez Cuen \\ Rosa María Burrola Encinas \\ Universidad de Sonora, México
}

Resumen

El principal objetivo de este artículo es el análisis de las novelas Tan cerca de la vida (2010) del peruano Santiago Roncagliolo y Ornamento (2015) del colombiano Juan Cárdenas. Interesa examinar cómo ambos textos representan la desarticulación de la idea del hombre en tanto conjunción entre cuerpo y alma, y escenifican un giro subjetivo en un sujeto posthumano y, con ello, se inscriben en una dimensión estética y cultural fundante de un nuevo realismo, encaminado a destejer las utopías fundantes de la literatura hispanoamericana y los marcos epistemológicos de la modernidad.

Palabras clave: literatura hispanoamericana, ciborg, posthumanismo.

Abstract

The primary goal of this article is the analysis of the novels Tan cerca de la vida (2010) by the Peruvian writer Santiago Roncagliolo and Ornamento (2015) by the Colombian writer Juan Cárdenas. We examine how both texts represent the disarticulation of the idea of man as a conjunction between the body and the soul, and show a subjective "twist" in a posthuman subject, as well registered in an aesthetic and cultural foundational dimension of a new realism and designed to unravel the foundational utopias of the Spanish-American Literature and the epistemological frames of the modernity.

Keywords: Spanish-American Literature, Ciborg, Post-humanism.

Recibido: 31 de diciembre de 2016 Aceptado: 23 de abril de 2017 


\section{Introducción}

Tna prodigiosa imaginación es una de las características más constantes con la que se ha distinguido a la literatura hispanoamericana. Esta condición se extiende a lo largo de la historia y de la geografía de la América Hispánica para gestar un extraordinario y abundante corpus que, en no pocos casos, ha resultado de difícil adscripción. Así, las definiciones de real maravilloso, realismo mágico y literatura fantástica, entre otras conceptualizaciones, frecuentemente se presentan en el discurso académico como elementos que se interceptan, que se implican o que simplemente se superponen.

En las últimas décadas a este complejo panorama se le suma una gran cantidad de textos en los que el cruce de ficción y ciencia desafía los modelos realistas. De este modo, en muchos casos influenciados por los procesos de globalización y por el avance de la ciencia y la tecnología, los jóvenes autores rompen con frecuencia el paradigma del escritor latinoamericano y practican una ficción que desborda el concepto tradicional de literatura nacional, surgen así, afirma Fernando Aínsa, un conjunto de obras en las que se ha diluido los referentes telúrico-biológicos de la identidad, para ahora cuestionar precisamente los supuestos donde, con frecuencia, ésta había descansado hasta hace pocas décadas (Aínsa, 2012: 61).

Esta narrativa refleja la ansiedad que la tecnología ha generado en las sociedades contemporáneas. Los escritores recientes retratan en sus textos comunidades multiculturales, caóticas y tecnificadas en las que cada vez resulta más evidente la manipulación de la verdad (Noguerol, 2008: 27). Con frecuencia se eligen escenarios posindustriales para dar cabida a nuevos paisajes urbanos y a historias desconcertantes, inspiradas en el cruce del arte y la ciencia. Así, se crea una literatura difícil de clasificar que se mueve entre 
cierta vertiente de lo fantástico, de la ciencia ficción y de un hiperrealismo anclado en un exceso de realidad.

Se trata de obras que operan en los límites de lo real y de lo fantástico, porque proyectan mundos inusitados y perturbadores a partir de la exploración de los efectos sociales y psicológicos de los avances tecnológicos y científicos en los individuos. Se convierte este cruce en un asunto fundante de una visión hiperracional en la episteme moderna. Estas narraciones, afirma Francisca Noguerol:

trabajan con las articulaciones y los efectos que producen diversas máquinas: la económica (aunque esta máquina podría incluirse dentro de la gran máquina de guerra), la de la visión o del espectáculo, la de la carne humana (que, como plantea Marcelo Cohen, es una red de instituciones que intervienen en la reproducción humana, la biología celular, la genética, la neurología, la cirugía, etc.) y, finalmente, la del lenguaje (Noguerol, 2008: 372).

En efecto, estas estéticas narrativas giran en torno a la incidencia de identidades posthumanas, las cuales parecen aflorar favorecidas por la hibridación entre lo local y lo global y a contracorriente de los modos dominantes de la narrativa latinoamericana del postboom y parecen entonces trazar una nueva tendencia de las letras hispanoamericanas; sin embargo, no está de más recordar que muchos de los escritores hispanoamericanos considerados canónicos se habían ya aproximado a estas temáticas. Esto se puede constatar desde los textos precursores de Arlt, donde los inventos parecen ocupar la imaginación de sus protagonistas, hasta en los del peruano Clemente Palma y, ya avanzado el siglo xx, podemos citar, sin afán de exhaustividad, a Horacio Quiroga, Adolfo Bioy Casares y Ricardo Piglia. Por lo menos desde principios del pasado siglo, podemos documentar el interés y las múltiples formas en las que la literatura hispanoamericana ha reflexionado sobre la relación y configuración de identidades a partir de los medios de los 
comunicación y de la influencia de la ciencia y de la tecnología, sin embargo, es probablemente a partir de los ańos setenta que se ha registrado un nuevo interés hacia las literatura que colocan en primer plano estas problemáticas.

Ahora bien, en muchas ocasiones las narraciones de las más recientes décadas erigen escenarios enrarecidos, oníricos y con frecuencia localizados en países lejanos o en territorios indefinidos en los que difícilmente se pueden identificar los referentes telúricos tan caros a buena parte de la literatura de los años sesenta, estas historias emergentes aparecen con frecuencia ligadas a tramas orientadas a analizar los procesos culturales actuales en Latinoamérica, y forjadas en torno a formas de crítica bio-política. Sus temáticas se centran en transformaciones biológicas, en el análisis de expresiones de violencia y de identidad, reflexiones todas de repercusiones locales y globales, acordes a las nuevas lealtades que manifiestan los jóvenes creadores hispanoamericanos, quienes dicen ya no sentirse anclados a su país de origen sino ligados a múltiples ciudadanías. Estas búsquedas implican nuevas respuestas a las acuciantes preguntas que asedian a sujetos y sociedades modernas en rápidos procesos de transformación. De ahí la irrupción con inusitada fuerza de temas que, aunque siempre habían estado en la historia de la literatura, ahora cobran renovada fuerza y significado, tales como los límites de lo humano y el uso del cuerpo como material para recreación e investigación.

La reflexión y representación en torno al cuerpo se adapta a las recientes formas de violencia, colonización y de organización económica, así como a las búsquedas actuales de identidad. Aunque hablamos de una narrativa que no comparte más la euforia de la América Latina postsesentista, no necesariamente se regodea en el desencanto o en el pesimismo, sino que simplemente parece asumir el fin de las utopías que alimentaron el pasado latinoamericano y observa sin ilusiones las lógicas sociales actuales. 
Se pensaría entonces un proceso natural donde la literatura acuda a las estéticas que ofrece el cruce de la ciencia ficción, la literatura fantástica y los nuevos realismos, para destejer las utopías fundantes de la literatura hispanoamericana y los marcos epistemológicos de la modernidad. Entonces, también puede resultar lógico que se desplieguen con especial corrosividad la crítica alrededor de las políticas sobre los cuerpos, el género, el consumo y el mercado, así como la reflexión en torno a los límites de las nuevas drogas de control y diseño de los estados de ánimo. Todos estos temas parecen encarnarse en la imitación o en el control de la carne para así dar cuenta de un estado de conciencia sumido en una hiperrealidad o en un simulacro de realidad. ${ }^{1}$

El análisis que a continuación proponemos sobre las novelas Tan cerca de la vida (2010) del peruano Santiago Roncagliolo y Ornamento (2015) del colombiano Juan Cárdenas gira en torno de estos tópicos. Interesa estudiar cómo ambos textos representan la desarticulación de la idea del hombre en tanto conjunción entre alma y cuerpo y escenifican un giro subjetivo en un sujeto posthumano y, con ello, se inscriben en una dimensión estética y cultural que, según Isabel Quintana: "plantea una nueva redistribución de lo sensible; es decir, que la producción de espacios conduce a un

${ }^{1}$ En el caso de la narrativa mexicana de ciencia ficción, podemos citar dos cuentos en los que se plantea el cuerpo como objeto experimental en futuros distópicos en los que el poder del estado cede ante el de las grandes compañías tecnológicas. El cuento "(e)" de Bernardo Fernández y Gerardo Sifuentes plantea el consumo de nuevos narcóticos electrónicos diseñados como una estrategia mercantil para eliminar a los empleados menos productivos de grandes compañías transnacionales. En el cuento "Yoni Rei" del también escritor mexicano Pepe Rojo, un sujeto ciborg da cuenta de su posicionamiento ante un sistema que, desde su nacimiento, lo ha convertido en un híbrido de lo mecánico y lo orgánico, ante lo que responde con la violentación de su mismo cuerpo, objeto de valor para la ciencia. En ambos, el consumo o la adopción de la tecnología responde a una necesidad de pertenencia en una sociedad que no deja lugar para la creación de vínculos afectivos. 
desplazamiento de la política (de lo hegemónico entendido como la articulación del sentido, las instituciones, la familia, etc.), a la formulación de lo político, como instancia primitiva de convivencia e incluso de sobrevivencia" (Quintana, 2012: 367).

\section{La representación del cuerpo en diálogo con la literatura y las artes plásticas}

El registro artístico del cuerpo ha permitido explorar el panorama universal de los distintos cánones sobre la belleza de la forma humana y, con ello, la posibilidad de observar los distintos epistemes en torno al cuerpo y su relevancia en la cultura, el arte, la economía, la política y la sociedad. Desde las artes plásticas hasta la poesía lírica, el arte ha girado desde sus inicios en torno a la exaltación, descripción o contemplación del cuerpo humano y, en particular, de la belleza femenina. Hoy en día, este poder contemplativo ha cedido ante el carácter crítico y reflexivo de nuevas expresiones artísticas en las que la identidad y el papel del sujeto es problematizado a partir de las representaciones que éste experimenta tanto de sí mismo como de su espacio.

Las nuevas configuraciones estéticas de la corporalidad rompen con el tradicional esquema de la erotización, y pasa a ser el eje convergente de ideologías, dinámicas de poder, relaciones de pertenencia e incluso de mercado. La respuesta ante la deshumanización correspondiente a las sociedades modernas es para narradores hispanoamericanos como Ernesto Sábato y Julio Cortázar: "un cierto tipo de humanismo literario donde las letras proveen la base para una re-humanización del cuerpo humano" (Brown y Sánchez Prado, 2008: 26), una forma de reivindicar esta sociedad por medio del discurso literario como conducto comunicativo. Irónicamente, en el caso de la literatura contemporánea más reciente, el cuerpo se perfila como un espacio en el que lo artificial 
y lo orgánico se debaten, polarizan y se mezclan al mismo tiempo, adquiriendo por medio de su construcción literaria una identidad que, al contrario de los postulados sustentados por los novelistas citados, deshumaniza el cuerpo humano.

Obras como Tan cerca de la vida y Ornamento narran y describen escenarios en los que la organicidad de sus personajes se ve manipulada por la intervención de la tecnología y el deseo de perfeccionamiento a partir de la integración de lo artificial. Carentes de la hiperbolización tecnológica propia de la ciencia ficción de finales del siglo XIX y principios del siglo XX, estas novelas parten de las posibilidades del cuerpo tecnológicamente modificado para replantear las relaciones humanas, las dinámicas de poder, el canon estético y la manera de pertenecer e integrarse en un contexto postmoderno marcado por el acceso a los avances tecnológicos y científicos.

Para el examen que proponemos hemos recurrido a las teorías sobre el sujeto ciborg, especialmente el manifiesto realizado por Donna Haraway y a los análisis alrededor del mismo tema del investigador Adrián Escudero. ${ }^{2}$ La definición de ciborg de Donna Haraway al comprender no sólo una ambigüedad en la naturaleza humana sino también un cambio en su formación identitaria y ontológica, resulta pertinente para este análisis narrativo debido a la capacidad de leer bajo una mirada filosófica y sociocultural,

${ }^{2}$ Cabe mencionar que aunque existe un extenso trabajo investigativo sobre posthumanismo en teóricos, entre los que destacan Katherine Hayles, Robert Pepperell (posthumanismo), Jill Didur (biopolítica), Mónica Cuervo Prados (ciborg), Gabriela Chavarría (transhumanismo) y Teresa Aguilar García (ciberontología); para fines de este ensayo es la propuesta fundacional de Haraway y el estudio de la identidad híbrida del ciborg y la interpretación de Escudero sobre corporalidades alternativas las que han proporcionado un apoyo teórico más directo para el análisis de las presentes novelas. 
discursos que aúnan ciencia, distopía, género y espacio. ${ }^{3}$ En el trabajo de la autora de "A Cyborg Manifesto: Science, Technology, and Socialist-Feminism in the Late Twentieth Century" (1991), además del estudio sobre la mecanicidad del cuerpo y sus posibilidades tecnológicas, se comprende la exposición de individuos transgénero, las modificaciones corporales y la incorporación de prótesis como algunos de los ejemplos de los que se ha valido el arte para reconocer estéticas alternas, pero también para expresar bajo una mirada crítica la forma en la que el desarrollo tecnológico ha impactado en la formación del sujeto contemporáneo. De acuerdo a Adrián Escudero: "se insiste una y otra vez en la misma idea: la disolución del sujeto, la fragmentación del yo, la dislocación de la subjetividad, la fungibilidad de las identidades, la contingencia de los roles sociales y, en términos más apocalípticos, la mutación del ser humano" (Escudero, 2007: 143).

Haraway define al ciborg en su manifiesto como un ser que aúna el carácter mecánico y el orgánico como una especie de formación híbrida y también liminal, ya que representa el estado intermedio entre dos naturalezas opuestas que deben comprenderse como una sola identidad: realidad/ficción, cultura/naturaleza, yo/ otro, mente/cuerpo o Dios/hombre. Si bien el manifiesto define el sujeto ciborg como un ser ambiguo, mixto y compuesto, la autora se centra en desarrollar las complejidades políticas y sociales que se derivan de los cambios tecnológicos producidos a finales del siglo

${ }^{3} \mathrm{El}$ acercamiento posthumanista de autores como Haraway en When species meet (2008) y Robert Pepperell en The posthuman condition (2003) también aborda la cuestión del fin del antropocentrismo en términos de inclusión para los estudios animales. Con esta ruptura del pensamiento antropocentrista como "esa larga creencia de la infalibilidad del poder humano y la arrogante creencia de nuestra superioridad y unicidad" (Pepperell, 171), estos estudios profundizan en las relaciones entre las especies humana y no humanas como parte de un nuevo proyecto de convivencia basado en la no explotación. 
XX y de qué manera se relacionan éstos con los estratos sociales más vulnerables o periféricos por motivos de género o raza.

Este eje sobre el proyecto de perfeccionamiento humano se ve desarrollado en las novelas de Roncagliolo y Cárdenas a partir de la superación de los límites corporales. La historia de Tan cerca de la vida transcurre durante la estancia de Max, personaje principal, en un hotel japonés donde se celebra una convención sobre robótica para la compañía en la cual trabaja. El nombre de la empresa, Corporación Géminis, representa el interés principal de su fundador por crear vida humana por medio de la reproducción mimética robotizada. El inventario de androides que circulan por la convención es una prueba de los repetidos y fallidos esfuerzos de conseguir dicho objetivo, y van desde diseńos funcionales y evidentemente mecánicos hasta autómatas de apariencia y comportamiento superficialmente humano, como un modelo infantil programado para amenizar musicalmente: "Su voz era delgada y aguda, su piel tersa y su mirada, inocente. Max sospechó que estaba ahí como un contraste con las piezas exhibidas, como una manera de decir: esto sí es natural. Pero al acercarse al pequeño y verlo de perfil, comprendió que también era una máquina, cubierta con fibra sintética e injertos de pelo" (Roncagliolo, 2010: 21).

La novela de Cárdenas debate entre la perfección del mundo orgánico y el mecánico, donde el cuerpo es el campo de batalla en el que la ciencia se opone a la naturaleza. Esta obra es narrada en torno a un supuesto idealismo científico, empeñado en el desarrollo de una nueva droga que optimiza el estado emocional de sus consumidoras, y cuyos resultados son registrados desde su experimentación en un grupo de mujeres voluntarias hasta su proceso de venta y su posicionamiento como una droga elitista y altamente adictiva. La inserción de este fármaco en el mercado rompe con el principio utópico de consumo equitativo sustentado inicialmente por la empresa y, al igual que los estándares de belleza a los que es- 
tán sometidos los personajes femeninos, se torna inasequible. Los personajes, la historia y los espacios se centran en la nueva droga, como se anuncia desde un principio con la ausencia de nombres propios de los personajes, identificados, en cambio, por su funcionalidad: el doctor, la esposa del doctor y las mujeres 2 y 4 , números de identificación utilizados durante el proceso experimental. A partir de esto es posible establecer un paralelismo entre el cuerpo como objeto mercantil y las relaciones de poder que parten de la economía y sus dinámicas de adquisición.

Uno de los ejes narrativos de Cárdenas y Roncagliolo es la posibilidad de una perfección humana que se debate entre el mundo natural y el universo tecnológico. Ambas novelas coinciden en el desarrollo de contextos en los que el avance científico implica una cierta superación de las capacidades humanas, argumentos que erigen una estética de lo artificial basada en el perfeccionamiento y en la contraposición de objeto y sujeto. Desde la re-construcción del paradigma de la belleza femenina a partir de las cirugías cosméticas hasta la robótica, la artificialidad se convierte en un elemento que impera tanto en la mímesis como en la hipérbole, pilares en la estética de la representación en estas novelas. En el caso de Tan cerca de la vida el nivel supremo de perfección y belleza ocurre según Kreutz, el líder de la corporación Géminis y creador de los autómatas, cuando el ojo humano es incapaz de distinguir el origen mecánico de una de sus creaciones. La imitación exacta consiste en el parámetro de lo bien hecho, mide el éxito de la robótica y representa una evolución del cuerpo ciborg por su parecido al cuerpo humano o del animal, como sucede en el caso del papagayo. El golem es el pájaro que acompańa al jefe de la corporación y que como tantas otras creaciones mecánicas de la novela ejemplifica el carácter ambiguo de la robótica por la perfecta imitación de las aves reales y que, "además de vistosas plumas multicolores y pico de loro, tenía la misma expresión, que Kreutz" (Roncagliolo, 2010: 23), lo que le 
otorga un aspecto de viveza. Como contraparte, en Ornamento el trabajo científico no aspira a la imitación del mundo natural, sino a la exageración de sus atributos estéticos. En la mujer número 2 la belleza se manifiesta en el "puro exceso" de sus cirugías, maquillaje y afeites y el atractivo de su aspecto, del que "parece muy orgullosa", se basa en la artificialidad de sus facciones: "ella me mira con ojos acuosos, detrás de sus lentes de contacto color esmeralda. Descanse, repito. La mirada verde persiste. Usted es muy bueno con nosotras, doctor, dice. Apenas atino a sonreír, desconcertado" (Cárdenas, 2015: 34). Así, cuando la imitación de la naturaleza humana deja de ser suficiente rasgo de excelencia tecnológica, se recurre a la exageración, como lo plantea Cárdenas al describir el poder de atracción de los cuerpos mutilados por las reconstrucciones cosméticas. En cuanto al mundo orgánico, los componentes naturales de ciertas plantas son manipulados para maximizar los efectos que tienen sobre las personas expuestas a ellos, como ocurre con un tipo de flor campestre que afectaba positivamente a las lavanderas de la región:

Un empleado de la zona que estaba de vacaciones por la zona observó que en algunas épocas del año las lavanderas de estos pueblos entraban en una suerte de éxtasis colectivo cuando bajaban al río a hacer su trabajo (suponemos que absorbían la sustancia de manera involuntaria por vía cutánea). De inmediato los gerentes y yo decidimos enviar a un equipo de becarios que regresó al laboratorio con muestras de los jabones y de las distintas flores utilizadas en su fabricación. Al cabo de unos meses ya habíamos conseguido sintetizar el principio activo (Cárdenas 35-36).

Según Jesús Adrián Escudero, para Haraway el ciborg se presenta como un transgresor de las fronteras que separan: "lo natural de lo artificial, lo orgánico de lo inorgánico y, de esa manera, rompe con el ideal de una esencia humana universal, dando pie a la proli- 
feración de múltiples identidades fracturadas expuestas al devenir de las circunstancias" (Escudero, 2007: 155). La fracturación de estas identidades, en términos de género, clase, educación, territorio y lengua, forman un panorama complejo del sujeto ubicado en el paradigma posmoderno y fungen como metáforas de la multiculturalidad, de la dilución de barreras sociales y de las dinámicas de sentido de pertenencia a partir de la adquisición o el ejercicio de la tecnología. El cuerpo, espacio limitado de monoidentidades es reivindicado de manera utópica por el desarrollo y la popularización de lo tecnológico, lo que supone una democratización del perfeccionamiento humano y social, gracias al efecto de las drogas en Ornamento y a las comodidades diarias obtenidas de la robótica en Tan cerca de la vida. En este sentido, el cuerpo mutante o ciborg actúa como una optimación del sujeto, siempre y cuando éste se encuentre inserto y activo en las dinámicas de adquisición, es decir, que sea económicamente solvente. Éste será uno de los puntos de quiebre que dan un giro a la historia de Cárdenas al convertir el proyecto de uniformidad social gracias a una droga estandarizada para las mujeres sin distinguir clases sociales, en un recurso destinado a la élite económicamente más privilegiada. Lejos de una lucha de clases se establece una rebelión de consumidores insatisfechos que, privados de un derecho adquisitivo, organizan motines, incurren en el robo e incluso asesinato, como lo hacen las mujeres que: "entraron a la casa del tipo armadas con revólveres, cuchillos, machetes", en un intento por despojar al proveedor de las pastillas y que como resultado dejó "como catorce mujeres muertas", según la versión del taxista que recuenta los hechos al doctor, protagonista de la novela.

La subversión de utopía a distopía no solamente ocurre en el sentido social, como en el caso de los ataques motivados por la demanda de la droga en Ornamento; también se presenta a partir de la ruptura de la perfección estética y el devenir de lo deforme y 
lo grotesco. En un episodio en el que el doctor y número 2 mantienen relaciones sexuales, la mujer es descrita a partir de las partes de su cuerpo al igual que el hombre, quien se ve a sí mismo: "como un adorno, como un firulete macizo, accesorio perplejo y poco grácil que le hubiera salido por la boca a ese rostro expansivo y sin centro" (Cárdenas, 2015: 126). El cuerpo cede ante la imagen del objeto y adquiere dimensiones estéticas aún más sublimes precisamente gracias a su cosificación, como también sucede en Tan cerca de la vida cuando la robótica logra imitar la naturaleza humana en su totalidad e incluso mejorarla. La dimensión sexual de los personajes femeninos que aparecen en la novela de Roncagliolo se ve polarizada entre lo humano y lo robótico y, en este orden, entre la parodia y el erotismo. En una de sus salidas nocturnas, Max, el protagonista principal de la novela, ingresa en lo que aparenta ser un prostíbulo y solicita por medio de un catálogo la compañía de una mujer de pelo rubio: "trabajosamente esculpido [...] parecía una novia intergaláctica. El amplio escote se abría en dos copas sólidas que levantaban su busto artificiosamente, y entre los pechos agonizaban los últimos restos de su escarcha" (Roncagliolo, 2010: 104). La mujer le resulta menos atractiva en persona que en su imagen impresa y admite que debido a un problema de comunicación por la incompatibilidad lingüística, LUCI, el prototipo robótico diseñado por la corporación "a su manera, le resultaba bastante más humana” que la supuesta prostituta. Más adelante se narra el primer encuentro entre Max y Mai, quienes si en un principio: "parecieron niños arrepentidos de haber planeado una travesura” (Roncagliolo, 2010: 175), y se muestran afables uno con el otro en su deseo de proporcionar placer, poco después pasan a ser descritos de acuerdo a un campo semántico de salvajismo y bestialidad en el que predomina la agresión.

Para Escudero: "los horrores y los desastres que sobrevienen al hombre cuando usurpa el poder creador de Dios" (Escudero, 2007: 
156), propios en la literatura gótica contemporánea al Frankenstein de Mary Shelley han dado paso a la representación de una "nueva carne" que, lejos de reflejar de manera negativa la ruptura del orden natural y divino a manos del ser humano: "insiste en la necesidad de controlar y mejorar la raza humana a través de la aplicación de los conocimientos científicos. El tema de fondo es la superación de los límites de la naturaleza y del cuerpo humano en aras de la conquista de la vida eterna y el placer" (Escudero, 2007: 156). Sin embargo, aunque de esta manera se presenten inicialmente ambas novelas, la sucesión de acontecimientos pone en diálogo, tal vez no las implicaciones éticas del desarrollo tecnológico, pero sí las de género, sociedad y mercado. En estas narrativas contemporáneas, las nuevas representaciones del cuerpo, en vez de ser puestas en diálogo a partir de la cuestión de género, son expuestas desde la mutilación, experimentación y cosificación que forman parte del proyecto de perfeccionamiento estético científico y tecnológico.

Si en las artes plásticas y en la literatura el registro y narración sobre el cuerpo forma parte de la representación de relaciones de poder basadas en género, etnia, pautas sociales y demás elementos culturales que conforman las identidades sociales e individuales, la llegada del sujeto ciborg sugiere una ruptura y una distorsión del modelo real del cuerpo como construcción del yo. La re-esquematización de la estética corporal a partir de la incorporación del objeto actúa en múltiples niveles para declarar un nuevo pensamiento crítico ante las políticas de representación de lo socialmente designado como estético. De la misma manera que Frankenstein personifica la monstruosidad al rebelarse ante el orden natural y orgánico -desde una perspectiva teológica que supone la rebelión ante el Creador-, los personajes de Cárdenas eventualmente dan cuenta de una naturaleza violentada y grotesca, como resultado de la intervención científica. Uno de ellos es la mujer denominada como número dos, quien forma parte del pequeño grupo feme- 
nino participante en los experimentos de la droga sintética y cuyo rostro está: "marcado por vaya a saber cuántas operaciones estéticas mal hechas, los labios como salchichas, la diminuta nariz de cerdo, las capas de maquillaje aplicadas como con espátula" (Cárdenas, 2015: 34); esta acumulación de procesos quirúrgicos mal realizados otorga al rostro de la mujer un estilo ornamental barroco marcado por: "puro exceso, un derroche de intenciones, el gasto por el gasto, el adorno fuera de control” (Cárdenas, 2015: 34). Esta representación nivela paralelamente la construcción del rostro femenino con el imaginario arquitectónico y hace de número dos un personaje portador de un estilo decadente, pero vigente dentro del canon estético de su contexto.

Más adelante, a pesar de la inicial repulsión que parecen causar en el doctor los procesos quirúrgicos que ha experimentado número dos, ésta será motivo de su deseo sexual y fungirá como un efímero consuelo ante el abandono de la esposa y de la amante. La descripción detallada sobre la estética del rostro de la mujer y las imágenes que número cuatro revive sobre el cuerpo modificado de su abuela forman parte del ornamento que Cárdenas intenta y logra definir en un contexto en el que predomina el mercado. Es así como la mujer número dos del experimento logra sobreponerse al mal estado de sus cirugías y presentarse como un sujeto atractivo, cuyo estilo si bien no se inserta en el canon estético tradicional, sí obedece a la lógica del mercado. El afán de alcanzar el perfeccionamiento físico por medio de las cirugías faciales y corporales forma parte de esta dinámica de inserción social, independientemente de los resultados finales. De la misma manera se presenta la droga sintética que uniforma a los sujetos femeninos bajo los criterios de género y perfecciona de manera temporal e individual el estado anímico de cada consumidora.

Las representaciones del ciborg subvierten la relación sujeto y objeto y promueven una nueva dimensión estética e incluso eróti- 
ca en el cuerpo. En cuestiones de género, la irrupción del sujeto ciborg en la escena artística supone una transgresión de las fronteras entre lo masculino y lo femenino, de acuerdo a la visión de Donna Haraway, donde: "the cyborg, as a hybrid creature, can support transgressing the boundary between male and female. Female embodiment has traditionally been identified with the organic and with mothering skills. As cyborgs, however, women can use new communications media to recreate themselves and go beyond previous constraints imposed on them by society" (Vicini, 2015: 151-152). Independientemente de la presencia de la robótica o de la naturaleza híbrida entre lo orgánico y lo mecánico, lo ciborg parece tener cabida a partir de la conjunción de ejes polarizados, la ruptura de barreras identitarias y la promulgación de nuevas formas de belleza, como un punto de partida para la transgresión estética y también ontológica. Es así como se logra validar la estética alternativa y periférica de número dos, de manera similar al trabajo de ciertos artistas fotográficos como Cindy Sherman en el que se pasa de figuras voluptuosas, seductoras, esculturales y atractivas a cuerpos tumefactos, sexualmente dominados e, incluso, reemplazados por diferentes elementos protésicos que, de alguna manera, anuncian la llegada del ciborg. Así, en las manifestaciones artísticas a las que nos referimos, el cuerpo deja de someterse al canon clásico de belleza para convertirse en el lugar de manifestación de los excesos tecnológicos y de las enfermedades sociales, de la fusión con lo mecánico, inorgánico y artificial (Escudero, 2007: 154).

La novela de Cárdenas bien podría reflejar la idiosincrasia consumista como una enfermedad social imperante en la ficción de su novela, aunque expone al mismo tiempo una realidad actual de su país de origen, Colombia. Los excesos tecnológicos de los que se hace mención no se presentan en el cuerpo de los personajes femeninos como esculturas semirobóticas, sino que crean un culto en torno al cuerpo operado, si no marcado con prótesis mecánicas 
como el ciborg tradicional, sí por la presencia del silicón y el bisturí. El resultado del cuerpo intervenido deviene un tanto paradójico cuando, en aras de alcanzar la belleza, la apariencia física se ve trastocada y da origen a un canon periférico reflejo de las prácticas culturales de una sociedad en declive, si pensamos en el decadente universo urbano representado por Cárdenas. En el caso de la droga, ésta es ideada como un estímulo sintético que optimiza el estado de ánimo de cualquier mujer, ya que: "no conoce distingos de clase, nivel adquisitivo o educativo entre las consumidoras, eso quiere decir que es posible una idea de democracia basada en el consumo" (Cárdenas, 2015: 85). Esta droga es calificada por su creador como artística, pero a diferencia del arte plástico de su mujer, ésta se aleja del elitismo aburguesado y resulta "feminista, igualitaria". Sin embargo, la inmediata dependencia origina una creciente demanda de quienes, al no ver satisfechas sus necesidades, acuden a la violencia y a los disturbios en las calles para conseguir las píldoras, situación antitética del inicial proyecto de unificación social ya que la medida para calmar los disturbios, es tornar inasequible la droga por medio del aumento de su precio.

La relación entre mercado y cuerpo es, tanto en la obra de Cárdenas como en la de Roncagliolo, un eje de partida para respaldar la legitimidad de la experimentación de la tecnología y la ciencia en el cuerpo humano, sobre todo en el femenino. En Ornamento: "el único espacio de legitimación es el mercado, o sea, el cuerpo y el mercado" (Cárdenas, 2015: 86), ya que, en los contextos descritos por los autores, el único código de conducta por el que se rigen los personajes es el de la oferta y la demanda y el de los modelos impuestos en cuestiones de estética y estilo de vida. Como asegura Lourdes Ventura, el cuerpo:

Aparece hoy más que nunca como un cuerpo-objeto, un cuerpo sometido a modelos externos, presionado por los cánones estéticos de un mercado unificador y asfixiante; un cuerpo que vive 
un extrañamiento de sí mismo mientras los gurús de la belleza programan con exactitud cómo deberían ser sus contornos; un cuerpo al que se invita constantemente, desde la publicidad, desde el ámbito laboral que reclama "buena presencia", desde el perfeccionismo familiar y el estatus económico, a un exhibicionismo que sólo encuentra su integración mediante el control aprobador de la sociedad (Ventura, 2000: 53).

Este control del que habla Ventura no solamente aparece en el personaje de número dos y su apariencia marcada por las cirugías cosméticas mal realizadas, ya que la madre de número cuatro también es representada a partir del paralelismo arquitectónico y la construcción del cuerpo como un objeto que, en plena decadencia, sigue siendo motivo de culto. Frecuentemente la madre es comparada por la hija con la casa en edad, apariencia y estado, quien en medio de un arrebato verbal causado por la ingestión de la droga experimental, da cuenta de escenas del pasado donde su madre es la protagonista:

a ella le gusta ser la cosa en la casa, la casa en la cosa: hubo un tiempo en que las casas se construyeron de acuerdo a los modelos de moda, el neoplasticismo, el funcionalismo, rinoplastismo, racional tropicalismo, mi madre, belleza tropical, arrancadora de suspiros, fabricante de asfixias y espasmos como un pasillo largo, infinito, sin ventanas sin puertas, ella debe de tener la misma edad que esta casa, ambas serían bellezas vintage si el testaferro no las hubiera empujado al abuso ornamental, a la refacción innecesaria, antifuncional, al retículo muerto que se adhiere a la cornisa (Cárdenas, 2015: 137).

La mención del testaferro, quien puede también identificarse como el esposo, no se repite a lo largo de la novela, aunque queda claro que es el responsable del exceso tanto cosmético como arquitectónico. Bajo esta lectura, este personaje masculino representa- 
ría en palabras de Ventura el "control aprobador de la sociedad", misma que apoya el perfeccionamiento del cuerpo a través de la negación del paso del tiempo. En el mismo monólogo citado arriba, el personaje número dos describe la apariencia de su madre desnuda, quien: "parece una muńeca de carne y hueso recién salida de la caja, no le cuelgan pellejos, se los recorta un cirujano muy bueno, tampoco tiene vello púbico y su vagina pelada y tersa, una vez eliminado el vello que la cubría, es la afirmación definitiva del ornamento" (Cárdenas, 2015: 137). La yuxtaposición de sujeto y objeto es inmediata, así como la pérdida de los referentes identitarios basados en edad y género, ya que la imagen de la mujer adulta es intercambiada por la de una muńeca, objeto emblemático de la infancia, al mismo tiempo que "la vagina que nunca aparece" niega su naturaleza sexuada gracias a su "prolijidad infantil [...] como una pequeńa pieza de alfarería india, el arabesco inesperado que cancela todos los espacios" (Cárdenas, 2015: 138).

caigo en su rostro que no es el umbral de ningún cuerpo, porque ahora sólo hay un cuerpo o sólo hay cabeza, no hay entradas ni salidas de ningún cuerpo, porque ahora sólo hay cuerpo o sólo hay cabeza, no hay entradas ni salidas de ningún cuerpo, las tetas como otras dos cabezas que sólo saben mirar hacia adentro, por encima del ombligo que parece mascullar algo y ahora soy yo, yo como una extensión del rostro (Cárdenas, 2015: 126).

Cabe cuestionar si la novela de Cárdenas permite releer el cuerpo como un nuevo territorio complejizado por las políticas y estéticas, como un espacio en el que las dinámicas sociales han cedido ante las mercantiles, a costa de la preservación de ciertos elementos identitarios. La intervención quirúrgica, la experimentación de sustancias somáticas artificiales y la manipulación científica descritas en esta narrativa dan cuenta del cuerpo como un objeto cuya funcionalidad se ve desplazada de la dimensión orgánica y bioló- 
gica hasta alcanzar el paralelismo de un complejo arquitectónico anunciado desde el título mismo de la novela.

En el caso de Roncagliolo, la robótica elude la exageración y el exceso visual presentes en Ornamento y mimetiza la naturaleza humana como manifestación de perfección tecnológica. La dicotomía entre artificio y naturaleza aparece de nuevo a partir del orden estético, en el que predomina la belleza por sí misma. En Tan cerca de la vida la ostentación se maneja a partir de la sobriedad y el engaño visual de los robots y de los sujetos ciborg, cuya artificialidad es expuesta a propósito con la finalidad de incrementar el contraste entre su naturaleza mecánica y su exterior aparentemente humano. Los androides que circulan libremente por la convención en la que se desarrolla la novela dan cuenta de ello al exponer, por una parte, el perfecto simulacro de vida humana $y$, por la otra, el carácter robótico, como se señala en una de las citas iniciales en las que el niño robotizado canta y es confundido con un niño de verdad.

La mímesis a la que aspira el jefe de la corporación Géminis con la creación de sus robots no intenta generar un engaño sobre su origen, sino presumir el poder de simulación que alcanza la ingeniería moderna, capaz de "crear" sujetos visual y funcionalmente similares a los seres humanos. En este sentido la robótica basa su estética en la autenticidad que supone lo sintético, como una forma de desplazar la asociación semántica entre artificio y falsedad. La estética que impera en la novela obedece a esta premisa en la que predomina la satisfacción sensorial y práctica ofrecida por la robótica y suspende los paradigmas éticos presentes en la tradición literaria con temas vinculados al desarrollo científico. En este sentido cada elemento mecánico de la obra resulta un recordatorio de las dos dimensiones de la vida (orgánica y mecánica) que la corporación intenta reunir en una sola a partir de sus creaciones ciborg. La flor "orgullosamente artificial" que Max regala a Mai como compensación por una disputa previa, ejemplifica la estética 
de lo artificial presente en la novela, al estar: "tan bien construida, era tan bella, que no necesitaba aparentar ser natural" (Roncagliolo, 2010: 126), ya que es precisamente la perfección que deviene del orden mecánico lo que plantea una estética superior a la imperfección del diseño orgánico.

\section{Conclusiones}

Si Max representa, de la misma manera que el golem, la posibilidad de una rebelión marcada por el enfrentamiento entre creador y objeto creado, las razones de sublevación entre los órdenes establecidos también obedecen a ciertas pautas, ya no míticas, sino económicas y sociales. Lejos de representar el deseo de superación sobre el creador, Max desea su propia independencia, la cual alcanza al ejercer su poder de elección cuando decide vivir y emprender una vida diferente con Mai. A su vez, este personaje rompe con el mutismo que la posicionaba en una escala evolutiva inferior a la de Max y se presenta como un ser comunicativo al relatar su historia pasada en un lenguaje compartido solamente por estos dos personajes. De la misma manera que el golem, Mai adquiere un sentido de libertad y deja de ser percibida como un sujeto pasivo.

En Ornamento, la rebelión de los personajes somatizados ocurre cuando se les niega la posibilidad de adquirir la droga y de una manera masificada, adquieren una autonomía colectiva que rompe con un orden económico establecido. En esta novela, a diferencia de la de Roncagliolo, la ruptura del orden y el enfrentamiento con el creador -en este caso el doctor que diseña la droga-, no tienen un carácter mítico, social o político, sino que se basa en las políticas de consumo. La sublevación se dirige a los líderes de mercado, el objetivo no se encuentra en valores abstractos sino en el objeto de consumo. En este sentido la autonomía de los personajes se logra con el alcance del poder adquisitivo, mismo que al ser nega- 
do conlleva a la opresión, la inconformidad y la limitación de la libertad adquisitiva.

Ante este planteamiento se puede apreciar una evolución del concepto ciborg desde el uso que Donna Haraway hace del término como una liberación de imposiciones, de género la mayoría de las veces, hasta el replanteamiento de imposiciones devenidas de las dinámicas sociales, culturales y económicas presentes en los escenarios latinoamericanos. Lejos de la utopía ciborg manejada por Haraway, la construcción ciborg entendida a partir del carácter híbrido del sujeto, replantea problemáticas presentes en todas las épocas, como el conflicto de clases, la otredad y el cuestionamiento sobre la identidad. Roncagliolo maneja en especial este último aspecto con la interrogante de Max sobre quién es y la manera en la que se construye su memoria.

El emergente crecimiento de narrativa con temática tecnológica, científica e incluso ciborg llama la atención por las nuevas formas de representar lo humano y lo artificial a partir de discursos que, o bien polarizan estos dos elementos por medio de su dicotomización o bien lo reúnen en un mismo cuerpo híbrido. Ya sea de una o de otra manera, estas construcciones dan cuenta de la forma en la que las identidades contemporáneas se plantean a partir de la adaptación y aceptación de la ciencia, al punto de hacer converger cuerpo y tecnología. Cárdenas y Roncagliolo muestran de distintas maneras la misma cara de una realidad que impera en la actualidad: el nuevo régimen ya no es el de la ciudad letrada, sino el del dominio tecnológico. Los términos para pertenecer a él ya no corresponden al poder político ni al mítico o intelectual, sino al poder adquisitivo que dispone el consumo de la tecnología y la participación de la ciencia. 


\section{Bibliografía}

Aínsa, Fernando, 2012, Palabras nómadas. Nueva cartografía de la pertenencia, Madrid/Frankfurt, Iberoamericana/Vervuert.

Brown, Andrew e Ignacio M. Sánchez Prado, 2008, "Humanismo cyborg: el letrado posthumano en América Latina”, Revista de Crítica Literaria Latinoamericana, año 34, núm. 68, LimaHanover NH, segundo semestre, pp.19-32.

Cárdenas, Juan, 2015, Ornamento, Cáceres, Periférica.

Escudero, Jesús Adrián, 2007, "El cuerpo y sus representaciones", Enrahonar, núm. 38/39, Bellaterra-Barcelona, pp. 141-157.

Fernández Delgado, Miguel A. (ed.), 2001, Visiones periféricas: antología de la ciencia ficción, México, Lumen.

Guerrero Almagro, Berta, 2012, "La superación de lo carnal en 'Tan cerca de la vida': una aproximación al posthumanismo", Cartaphilus, vol. 10, Murcia, pp. 109-120.

Haraway, Donna J., 1991, "A Cyborg Manifesto: Science, Technology, and Socialist-Feminism in the Late Twentieth Century", en Simians, Cyborgs, and Woman. The Reinvention of $\mathrm{Na}$ ture, Routledge, New York-Milton Park, pp. 149-181.

Montfort, J.S. de, 2015, "Lo más importante es la educación", Revista electrónica Hermanocerdo. Disponible en: http:// hermanocerdo. com/ 2015/ 02/ lo-mas-importante-es-la-educacion/

Noguerol, Francisca, 2008, "Narrar sin fronteras", en Entre lo local y lo global. La narrativa latinoamericana en el cambio de siglo (1990-2006), Jesús Montoya Juárez y Ángel Esteban (eds.), Madrid/Frankfurt, Iberomaericana/Vervuert, pp. 19-33.

Quintana, Isabel, 2012, "Ficciones de lo (in)humano: biopolítica, ciencia-ficción y fantástico", Revista Iberoamericana, vol. 78, núms. 238-239, Pittsburgh, enero-junio, pp. 367-386. 
Roncagliolo, Santiago, 2010, Tan cerca de la vida, México, Alfaguara.

Ventura, Lourdes, 2000, La tiranía de la belleza, José Antonio Marina (prol.), Barcelona, Plaza \& Janés.

Vicini, Andrea y Agnes M. Brazal, 2015, “Longing for Transcendence: Cyborgs and Trans- and Posthumans", Theological Studies, vol. 76, núm. 1, marzo, pp.148-165. 